\title{
Palliative and end-of-life care in
}

\section{advanced renal failure}

Lynne Russon, consultant in palliative medicine, Leeds Teaching Hospitals NHS Trust and Sue Ryder Care, Wheatfields, Leeds; Andrew Mooney, consultant renal physician, Leeds Teaching Hospitals NHS Trust

End-of-life care for renal patients has previously been inadequate. Such patients have been more likely to die in hospital than many other patients, ${ }^{1}$ and the symptoms of dying might not historically have been fully recognised by renal physicians caring for them. ${ }^{2,3}$ The need for specialist palliative care for patients with advanced chronic kidney disease (CKD) has now been recognised.

Part 2 of the National Service Framework for Chronic Kidney Disease ${ }^{4}$ includes a quality requirement for endof-life care and recommends a jointly agreed palliative care plan with renal networks establishing links with palliative care services. This is reinforced by the end-of-life care strategy. ${ }^{5}$ A framework for implementation ${ }^{6}$ has also been produced which sets out how to achieve these goals.

There is a recognised role for palliative care in patients choosing to withdraw from dialysis, perhaps due to a new diagnosis of terminal illness or progression of comorbidity. There is also a growing role to provide care for patients with advanced CKD who choose not to receive dialysis at all.

\section{Classification}

The introduction of the Modification of Diet in Renal Disease formula for estimating glomerular filtration rate (GFR) in CKD has led to the classification of CKD into five stages (Table 1). ${ }^{7}$ Advanced kidney disease (AKD) refers to patients with late stage 4 and stage 5 .

\section{Incidence of renal impairment in the general and palliative care population}

Following the introduction of this assessment of renal function, studies have revealed that a large proportion of the population is affected, with as many as $5 \%$ of adults having CKD stage 3 or worse. ${ }^{8}$ The prevalence is particularly high among elderly patients and those with comorbidity, so the burden might be even higher among patients in the palliative care population. Progression of renal failure is common among these patients, occurring in about three-quarters of them. ${ }^{9,10}$ However, the number ultimately receiving dialysis is very small, emphasising the need for development of endof-life services for this cohort of patients.

\section{Symptom control in advanced kidney disease}

Patients with AKD have significant symptom control needs, with a symptom profile similar to patients with advanced

Table 1. Classification of chronic kidney disease. ${ }^{7}$

\begin{tabular}{lll} 
Stage & GFR $(\mathrm{ml} / \mathrm{min})$ & Description \\
\hline 1 & $>90$ & $\begin{array}{l}\text { Normal kidney function, but urine findings, structural abnormalities } \\
\text { or genetic trait point to kidney disease } \\
\text { Mildly reduced kidney function, but other findings (as for stage 1) } \\
\text { point to kidney disease }\end{array}$ \\
3 & $60-89$ & $\begin{array}{l}\text { Moderately reduced kidney function } \\
4\end{array}$ \\
5 & $15-29$ & $\begin{array}{l}\text { Severely reduced kidney function } \\
\text { End-stage kidney failure (established renal failure) }\end{array}$ \\
\hline GFR = glomerular filtration rate.
\end{tabular}

cancer. ${ }^{11}$ The most common symptoms include fatigue, breathlessness, pain and itch (Table 2). There are also significant psychological, social and spiritual needs, including coming to terms with their changing role, increasing dependency and financial loss.

\section{Prescribing for symptoms}

\section{Advanced chronic kidney disease}

Pain. Pain in renal failure is often related to renal bone disease and poorly addressed due to anxiety about prescribing and poor recognition.

Codeine and morphine should be avoided in renal failure. If taken regularly, their toxic metabolites, which are renally excreted, accumulate and can quickly cause over-opiation. Clinical trial evidence on the use of strong opioids in renal failure is limited, but in clinical practice oxycodone is better tolerated than morphine and may be used for patients with GFRs of $50-20 \mathrm{ml} / \mathrm{min}$. The metabolites of oxycodone also accumulate and, as GFR falls, lower doses of oxycodone and a longer dose interval may be needed.

When GFR falls below $20 \mathrm{ml} / \mathrm{min}$, buprenorphine and fentanyl preparations should be used. Buprenorphine and fentanyl preparations are better tolerated in severe renal impairment because their metabolites are largely inactive and

Table 2. Symptom prevalence in patients with stage 5 chronic kidney disease. $^{12}$

\begin{tabular}{ll} 
Symptom & $\begin{array}{l}\text { Weighted mean } \\
\text { prevalence (\%) }\end{array}$ \\
\hline Fatigue & 71 \\
Pruritus & 55 \\
Constipation & 53 \\
Anorexia & 49 \\
Pain & 47 \\
Muscle cramps & 46 \\
Poor sleep & 44 \\
Anxiety & 38 \\
Dyspnoea & 37 \\
Nausea & 33 \\
Restless legs & 30 \\
Depression & 27 \\
\hline
\end{tabular}


excreted by the liver. When patients have stable analgesic requirements, transdermal buprenorphine patches may be used for those requiring small to moderate doses, or fentanyl patches if a higher dose is required. Either fentanyl or alfentanil can be used in a syringe driver if more dose flexibilty is needed when GFR is less than $20 \mathrm{ml} / \mathrm{min}$ and at the end of life. ${ }^{13}$

Theoretically, methadone shows little accumulation but has wide interpatient variation and a narrow therapeutic index. It should not be used without specialist advice. ${ }^{14}$

Non-steroidal anti-inflammatory drugs (NSAIDs) alter glomerular haemodynamics and, as such, are nephrotoxic. They should be used with caution in patients with severe renal impairment, but may be appropriate when the benefits outweigh the burdens such as in the last few days of life. There is no strong evidence that one NSAID has significant 'renal advantages' over any other.

Neuropathic pain. Amitriptyline should be titrated from low doses such as $10 \mathrm{mg}$ once daily. No dose adjustment is required.

Gabapentin and pregabalin require significant dose adjustments. The maximum dose of gabapentin with a GFR of less than $30 \mathrm{ml} / \mathrm{min}$ is $300 \mathrm{mg}$ daily. If the GFR is below $20 \mathrm{ml} / \mathrm{min}$, very small doses of gabapentin such as $50 \mathrm{mg}$ od are often effective.

Nausea. Patients with renal failure frequently have a chemical cause for nausea and vomiting. Haloperidol, ondansetron and granesitron are therefore the most effective anti-emetics. Levomepromazine is also useful as an antiemetic and sedative in the terminal stages. Haloperidol and levomepromazine have increased sedative effects in renal failure so doses should be reduced, particularly when GFR is less than $10 \mathrm{ml} / \mathrm{min}$, and titrated accordingly. If a prokinetic antiemetic is required, metoclopramide is well tolerated but the dose needs to be reduced when GFR is below $20 \mathrm{ml} / \mathrm{min}$.

Pruritus. Renal osteodystrophy results in low calcium and high phosphate levels, the latter inducing itch. This can be treated by preparations which bind dietary phosphate in the gut. Renal patients tend to have dry, and therefore itchy, skin which can be relieved by regular use of a simple moisturiser such as aqueous cream.

Uraemia can also cause itching, usually when GFR is below $10 \mathrm{ml} / \mathrm{min}$. Antihistamines are not particularly helpful for uraemic itch. There is some evidence that ondansetron, a 5-hydroxytryptamine- 3 receptor antagonist, may help both nausea and itch in these patients and that low-dose gabapentin may relieve uraemic itch. ${ }^{15}$

\section{Renal replacement therapy}

Patients on dialysis who require palliative care should, on the whole, be treated in the same way as patients with severely impaired GFR not on dialysis. In peritoneal dialysis, clearance rates of drugs are constant and the timing of doses not important. On haemodialysis, patients will be receiving intermittent treatment but only rarely do drug administration times need adjusting. Dialysis clears non-proteinbound water-soluble drugs of low molecular weight, so usually only intravenous antibiotics need to be adjusted occasionally. The agents described above can be used at any time during the 'dialysis cycle'.

\section{Conservative management for end-stage renal failure}

Many renal services have developed specialised clinics to review patients with significantly impaired GFRs. In our service in Leeds, when GFR falls below $20 \mathrm{ml} / \mathrm{min}$ patients are offered education to choose between different treatment modalities haemodialysis, peritoneal dialysis or transplantation - after which preparations for their chosen treatment are made (Fig 1).

\section{No dialysis}

A further choice is now offered: no dialysis. Patients making this choice are reviewed by a palliative medicine consultant within the renal clinic, and therefore still receive regular medical, nursing and dietetic review, and management of their anaemia to minimise fatigue. However, a greater emphasis is placed on symptom control and social support with a dedicated social worker. These patients tend to be elderly with multiple comorbidities, but as many as one in six patients in our service snow choose this treatment option. There is evidence that patients over 75 years with multiple comorbidities, particularly ischaemic heart disease, may not increase their longevity as a result of receiving dialysis. ${ }^{16}$

Renal function is monitored regularly, so that this can be optimised and used as

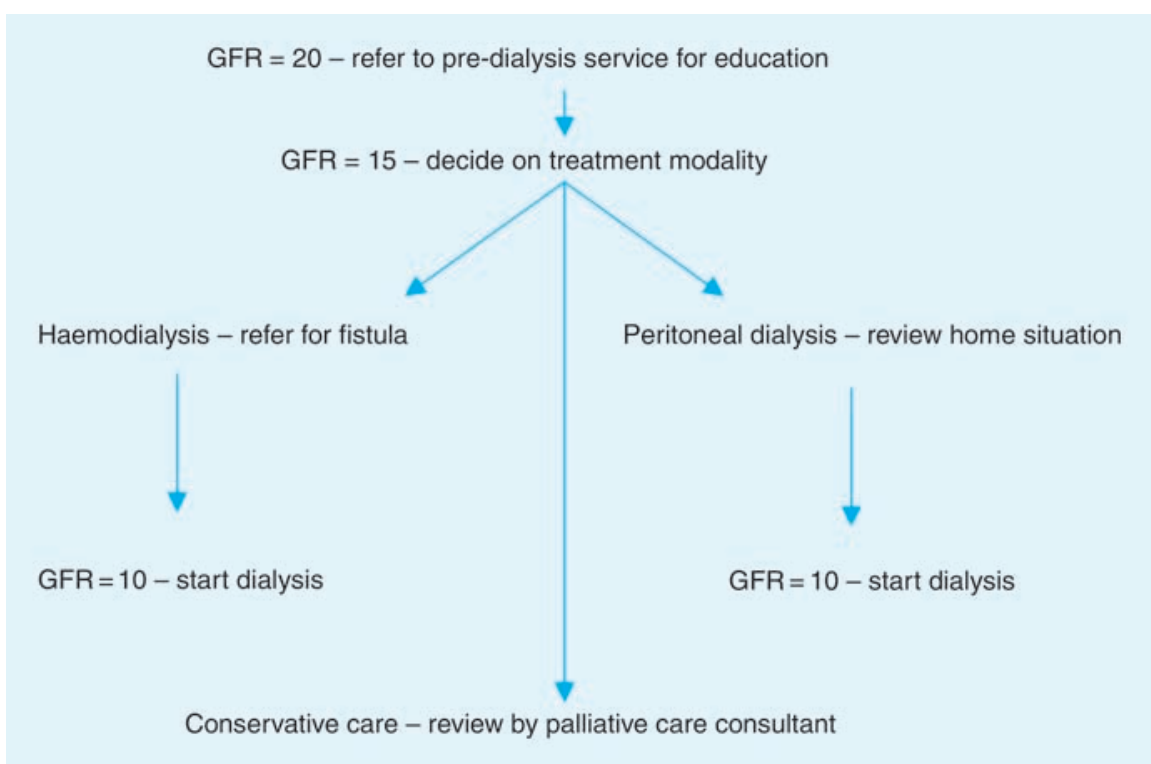

Fig 1. Management options for patients in end-stage renal failure. GFR = glomerular filtration rate. 
Key Points

There is increasing recognition of the gap in service provision of palliative care for patients with advanced kidney disease (AKD)

Patients with AKD have significant symptom control needs. Symptoms are poorly addressed due to poor recognition and anxiety about prescribing

There are rising numbers of patients with AKD who choose not to have dialysis (conservative care)

This population of patients are usually elderly with multiple comorbidities and are more likely to die in hospital

Advance care planning is an essential part of the renal palliative care clinic and is essential to meet end-of-life priorities of care

KEY WORDS: advance care planning, advanced kidney disease, conservative management, end of life

a prognostic marker. Phosphate and calcium levels and vitamin D metabolism are also monitored and treated with diet and medication. Uraemic symptoms are assessed and palliated.

Patients who choose to be treated conservatively may continue to live with very low GFRs for some time, but approximately $75 \%$ will die within the year. ${ }^{17}$ Patients opting for conservative treatment tend to die when their GFR reaches approximately $5 \mathrm{ml} / \mathrm{min}$.

Patients who withdraw from established dialysis have a mean survival of 8-11 days. ${ }^{18}$ Advance care planning should therefore ideally start before dialysis is withdrawn.

\section{Advance care planning}

Advance care planning is the process of discussion between an individual and their healthcare professional about future needs. ${ }^{19}$ Helping a patient establish their priorities in end-of-life care enables them to plan their future and prepare for death, allowing them to maintain control over their wants and wishes. ${ }^{20}$ Preferences should be communicated to all professionals involved and documented appropriately. There is a significant mismatch between people's preferences regarding where they should die and their actual place of death. Most patients prefer to die at home, but most renal patients tend to die in hospital. ${ }^{1}$

\section{Summary}

There is a recognised need to provide palliative care services for patients with AKD. Such services can improve end-oflife care for patients withdrawing from dialysis and those choosing not to have dialysis. Developments in such services should lead to measurable advances in patients' experiences.

\section{References}

1 Smith C, Da Silva-Gane M, Chandna S et al. Choosing not to dialyse: evaluation of planned non-dialytic management in a cohort of patients with end stage renal failure. Nephron Clin Pract 2003;95:c40-6.

2 Levy JB, Chambers EJ, Brown EA. Supportive care for the renal patient. Nephrol Dial Transplant 2004;19:1357-60.

3 Davison SN. Pain in hemodialysis patients: prevalence, cause, severity, and management. Am J Kidney Dis 2003;42:1239-47.

4 Department of Health. National Service Framework for Renal Services. Part 2: Chronic kidney disease, acute renal failure and end of life care. London: DH, 2005.

5 Department of Health. End of Life Care Strategy: promoting high quality health care for all adults at the end of life. London: DH, 2008.

6 Department of Health. End of life care in advanced kidney disease: a framework for implementation. London: DH, 2009.

7 National Institute for Health and Clinical Excellence. Chronic kidney disease: early identification and management of chronic kidney disease in adults in primary and secondary care. Clinical guideline CG73. London: NICE, 2008.

8 Snyder JJ, Foley RN, Collins AJ. Prevalence of CKD in the United States: a sensitivity analysis using the National Health and Nutrition Examination Survey (NHANES) 1999-2004. Am J Kidney Dis 2009;53:218-28.

9 Drey N, Roderick P, Mullee M, Rogerson M. A population-based study of the incidence and outcomes of diagnosed chronic kidney disease. Am J Kidney Dis 2003;42:677-84.

10 Eriksen BO, Ingebretsen OC. The progression of chronic kidney disease: a 10-year population-based study of the effects of gender and age. Kidney Int 2006;69:375-82.

11 Saini T, Murtagh FE, Dupont PJ et al. Comparative pilot study of symptoms and quality of life in cancer patients and patients with end stage renal disease. Palliat Med 2006;20:631-6.

12 Murtagh FE, Addington-Hall JM, Edmonds PM et al. Symptoms in advanced renal disease: a cross-sectional survey of symptom prevalence in stage 5 chronic kidney disease managed without dialysis. J Palliat Med 2007;10:1266-76.

13 Ashley C, Currie A (eds). The Renal Drug Handbook, 3rd edn. Oxford: Radcliffe Medical Press Ltd, 2009.

14 Yorkshire Palliative Medicine Guidelines Group. Clinical guidelines for the use of palliative care drugs in renal failure. Leeds: YPMGG, 2007. Available at www.palliativedrugs.com

15 Gunal AI, Ozalp G, Yoldas TK et al. Gabapentin therapy for pruritus in haemodialysis patients; a randomised, placebo-controlled, double-blind trial Nephrol Dial Transplant 2004;19:3137-9.

16 Murtagh FE, Marsh JE, Donohoe P et al. Dialysis or not? A comparative survival study of patients over 75 years with chronic kidney disease stage 5. Nephrol Dial Transplant 2007;22:1955-62.

17 Russon L, Ackroyd R, Crowther R et al. Palliative care for renal patients, the first three years. Palliat Med 2010;24:235-6.

18 Birmelé B, François M, Pengloan J et al. Death after withdrawal from dialysis: the most common cause of death in a French dialysis population. Nephrol Dial Transplant 2004;19:686-91.

19 Royal College of Physicians. Advance care planning. London: RCP, 2009.

20 Davison SN, Torgunrud C. The creation of an advanced care planning process for patients with ESRD. Am J Kidney Dis 2007;49:27-36.

Address for correspondence:

Dr L Russon, Leeds Teaching Hospitals NHS Trust and Sue Ryder Care, Wheatfields, Grove Road, Headingley, Leeds LS6 2AE. Email: lynne.russon@suerydercare.org 